\title{
Social support and post-traumatic growth among a sample of arthritis patients: Analysis in light of conservation of resources theory
}

\author{
Jessica Sörensen ${ }^{1} \cdot$ Marcin Rzeszutek ${ }^{1} \cdot$ Robert Gasik $^{2}$
}

Published online: 18 January 2019

(C) The Author(s) 2019

\begin{abstract}
The study examined the association between social support dimensions and post-traumatic growth (PTG) among a sample of arthritis patients. In particular, we wanted to verify the mediating role of resources, as described by the Conservation of Resources (COR) theory, on the aforementioned relationship. A total of 207 patients with a clinical diagnosis of arthritis were recruited to participate in the study, including 149 females and 58 males. This was a cross-sectional study, with PTG evaluated by the PostTraumatic Growth Inventory (PTGI) and social support assessed via the Berlin Social Support Scales (BSSS). To assess the level of subjectively possessed resources among participants, we used the COR evaluation questionnaire (COR-E). Provided support, but not received support, was positively related to the level of PTG among participants. In addition, the level of spiritual resources mediated the aforementioned relationship. The results of this contribute to the literature on the psychological aspects of arthritis. It seems that providing support may be related to positive consequences among arthritis patients, in the form of PTG, with spiritual resources being of significant value in this process.
\end{abstract}

Keywords Arthritis · Post-traumatic growth $\cdot$ Social support $\cdot$ Conservations of resources (COR) theory

Arthritis is currently one of the leading chronic diseases in the general population (Jafarzadeh and Felson 2017; Smolen et al. 2016). Several authors have observed that the diagnosis and struggle with this disease is connected with multiple negative physical and psychosocial consequences. More specifically, disability among these patients results in an inability to work, higher probability of long-term sickness absence and disability pension, higher unemployment and restricted leisure activities (Hansen et al. 2017; Wikström et al. 2006). Thus, there is a higher prevalence of psychiatric disorders, especially anxiety and depressive symptoms, among these individuals, including a higher risk of

Jessica Sörensen

jessicasorensen@hotmail.com

Marcin Rzeszutek

marcin.rzeszutek@psych.uw.edu.pl

Robert Gasik

robertgasik2@gmail.com

1 Faculty of Psychology, University of Warsaw, Stawki 5/7, 00-183 Warsaw, Poland

2 National Institute of Geriatrics, Rheumatology and Rehabilitation, Spartańska 1, 02-637 Warsaw, Poland suicide as compared to the general population (Kotsis et al. 2012; Matcham et al. 2013; Shen et al. 2016; Tang and Crane 2006). Additionally, several sleep disorders and substance-abuse problems have been observed in patients with arthritis diseases (Edlund et al. 2013; Roddy et al. 2013; Taylor-Gjevre et al. 2011).

As described above, the vast majority of psychological research on arthritis patients points only to the negative consequences of this illness. However, with the advent of positive psychology (Seligman and Csikszentmihalyi 2000), several researchers have also focused on the paradoxically positive changes accompanying traumatic or highly stressful life events, including the specific case of struggling with chronic disease (Hefferon et al. 2008). A topic related to this phenomenon is post-traumatic growth (PTG), which occurs when an individual experiences highly challenging life events that manifest as profound transformations in several functional aspects of life, such as improved social relationships, seeking new life paths, a greater appreciation of life, openness to spirituality and awareness of personal strength (Tedeschi and Calhoun 1996, 2004). PTG is influenced by sociodemographic characteristics of trauma survivors and the type of traumatic event that is challenging enough to force an individual to engage in cognitive processing of trauma and adapt to a new situation (Calhoun et al. 2010; Frankl 1992; Tedeschi 
and Calhoun 2004). These ruminative thoughts are negative and intrusive at first, but with time elapsed ruminations become less intrusive and positive in order to find meaning of trauma and new priorities in life, which is the core mechanism leading to PTG (Tedeschi and Calhoun 1996, 2004).

Arthritis is a chronic, debilitating and painful condition with many negative consequences and threats to patients' physical and mental health, including shortened life expectancy and increased mortality compared to the general population (Smolen et al. 2016). Therefore, it can be treated as a trauma, which causes the patient to challenge the view of self and world and develop PTG (Rzeszutek et al. 2017b). Particularly, some authors observed the link between arthritis diseases and PTG, i.e. enhanced appreciation of life, better relationships with others and personal strength as a result of struggling with this illness (Abraido-Lanza et al. 1998; Dirik and Karanci 2008; PurcStephenson 2014). More specifically, the level of PTG in arthritis was related to lower levels of depression and disability as well as to better adjustment to the illness (Danoff-Burg and Revenson 2005; Sirois and Hirsch 2013). Finally, chronic illness, viewed as a traumatic experience, is a threat that requires mobilization of social support and coping processes, which could be viewed as individual and social resources, and according to some studies be more accessible with time (O’Leary and Ickovics 1995; Klauer et al. 1998). Traumatic events are also associated with resource change. Availability and change in resources can help in coping with stress and are associated with certain consequences, including adaptive and positive outcomes (Banou et al. 2009).

The psychosocial resource which is above all correlated with PTG in this patient group is social support. This is in line with Tedeschi and Calhoun's model of PTG (Tedeschi and Calhoun 1996, 2004), in which social support may promote PTG by stimulating cognitive processing after trauma, especially with regard to finding meaning after traumatic or highly stressful life events. The majority of authors who have examined the role of social support (perceived support) found it to be positively related to PTG among these patients (Nenova et al. 2011; Rzeszutek et al. 2017b). Previous studies have reported an association between PTG and mainly received or perceived support, including studies conducted on arthritis patients (Rzeszutek et al. 2017a; Sato et al. 2008). In our research, however, we also wanted to observe the relationship between provided support and PTG. The idea of the mixed blessing of received support is widely known in literature (Gleason et al. 2008). Specifically, receiving support may evoke feelings such as guilt and distress, negatively affecting the well-being of the recipient of support (Bolger et al. 1996; Scholz et al. 2012). By contrast, provided support might function as a distraction in patients and increase their levels of selfesteem and feelings of independence (Batson and Powell 2003), thus being positively related to patients' well-being (Kleiboer et al. 2006; Morelli et al. 2015). However, there is still limited research related to the occurrence of PTG among arthritis patients, especially in relation to other social support dimensions (e.g., received support and provided support).

Taking into account the high psychological distress among arthritis patients, it is important to investigate ways in which these patients may cope with the high psychological burden associated with the illness (Dager et al. 2011; Shih et al. 2006). Until now, a great deal of research has been carried out on the role of coping among arthritis patients (e.g., Benka et al. 2014; Evers et al. 2003), mostly based on the Lazarus and Folkman's (1984) model, which primarily underlines the role of individual cognitive appraisal of the illness as the key factor in coping with disease-related distress. Nevertheless, arthritis, like other chronic diseases, encompasses major changes in various elements of a patient's social life (Shih et al. 2006). Specifically, significant disparities have been found among arthritis patients in access to several social and environmental resources (Goeppinger et al. 2007). In this paper, therefore, we refer to the Conservation of Resources (COR) theory (Hobfoll 1989) which is much understudied in this context. The COR theory was incorporated in this study due to the perception that Lazarus and Folkman's model puts great emphasis on subjective cognitive appraisal in the process of stress-coping while the COR theory includes objective psychosocial aspects of stress as well (Hobfoll 1989). The COR theory argues that stress takes place when one's resources are lost or threatened or when there is a lack of gain from invested resources. Diverse types of resources that an individual values are defined as object resources, condition resources, personal resources and energy resources (Hobfoll 1989). Some authors have found that COR resources are related to adaptation to chronic illness, usually acting as mediators between psychosocial variables and illness-related distress (e.g., Banou et al. 2009; Hou et al. 2010). With respect to arthritis patients, one study revealed that the majority of patients experienced resource loss which further predicted anxiety and depression (Dirik and Karanci 2009). The COR theory has been examined with regard to PTG (e.g., Hobfoll et al. 2006; Hollifield et al. 2016), but, to our best knowledge, no study has been conducted on the role of resources (as described by the COR theory) and PTG following chronic illness. Therefore, this study may fill an important research gap.

\section{Current Study}

The aim of this study was to examine the association between social support dimensions (received and provided support) and PTG among a sample of arthritis patients. In particular, we wanted to verify the mediating role of resources as described by the COR theory on the aforementioned relationship while controlling for selected socio-medical data. We formulated two hypotheses: 
Hypothesis 1. There is a positive relationship between the level of received and provided support and the level of PTG among participants.

Hypothesis 2. The relationship mentioned in the first hypothesis is partially mediated by the level of resources as defined in the COR theory (i.e., hedonic and vital resources, spiritual resources, family resources, economic and political resources and power and prestige resources).

\section{Method}

\section{Participants and Procedure}

The study sample comprised 207 adults with a clinical diagnosis of arthritis. The patients were recruited from the National Institute of Geriatrics, Rheumatology and Rehabilitation in Warsaw, the Clinical Department of Internal Diseases and Rheumatology of the Central Clinical Hospital of the Ministry of the Interior and Administration in Warsaw and the Internal Medicine and Rheumatology Clinic of the Military Institute of Medicine in Warsaw. Of the 297 patients eligible for the study, 207 were recruited (69.7\%), 38 declined (12.8\%) and $52(17.5 \%)$ could not be contacted due to appointment changes or persistent pain. Of the 207 recruited patients, 142 suffer from rheumatoid arthritis, 18 from psoriatic arthritis, 36 from ankylosing spondylitis and 11 patients from a gout diagnosis.

The participants filled out a paper-and-pencil questionnaire and participated in the study voluntarily, there being no remuneration for participation. The eligibility criteria encompassed participants 18 years of age or older with a confirmed medical diagnosis of arthritis. The exclusion criteria included patients in the process of diagnosis or lack of an arthritis diagnosis. The research project was approved by the ethics committee. Table 1 presents the socio-medical characteristics of the study sample.

\section{Measures}

To assess the level of PTG, a Polish adaptation (Ogińska-Bulik and Juczyński 2010) of the Post-Traumatic Growth Inventory (PTGI) (Tedeschi and Calhoun 1996) was used. It should be emphasized that the original PTGI comprises five specific domains of PTG ('relating to others', 'new possibilities', 'personal strength', 'spiritual change', and 'appreciation of life'), while the Polish adaptation of the PTGI included only four domains of PTG. Exploratory and confirmatory factor analyses revealed a four-factor structure for PTG, including changes in selfperception ('perceiving new possibilities' and 'feeling of personal strength'), changes in relationships with others ('feelings of greater connection with other people, increase in empathy,
Table 1 Socio-medical variables in the studied sample $(N=207)$

\begin{tabular}{ll}
\hline Variable & $\mathrm{N}(\%)$ \\
\hline Gender & \\
Male & $58(28 \%)$ \\
Female & $149(72 \%)$ \\
Age in years $(\mathrm{M} \pm \mathrm{SD})$ & $51.70 \pm 14.10$ \\
Marital status & \\
Married & $159(76.8 \%)$ \\
Single & $76(23.2 \%)$ \\
Education & \\
Elementary & $36(17.4 \%)$ \\
Secondary & $87(42 \%)$ \\
University degree & $84(40.6 \%)$ \\
Employment & \\
Full employment & $99(47.8 \%)$ \\
Unemployment & $21(10.1 \%)$ \\
Retirement & $34(16.4 \%)$ \\
Sickness Allowance & $53(25.6 \%)$ \\
Place of residence & \\
Village, small town up to 20 thousand residents & $69(33.3 \%)$ \\
City 21 to 100 thousand residents & $50(24.2 \%)$ \\
City 101 to 500 thousand residents & $16(7.7 \%)$ \\
City over 500 thousand residents & $72(34.8 \%)$ \\
Lack of a permanent place of residence & 0 \\
Duration of disease in years $(\mathrm{M} \pm \mathrm{SD})$ & $9.57 \pm 10.74$ \\
Duration of treatment in years $(\mathrm{M} \pm \mathrm{SD})$ & $9.77 \pm 10.27$ \\
\hline
\end{tabular}

$M$, mean; $S D$, standard deviation

altruism'), greater appreciation of life ('changes in life philosophy and current life goals, greater appreciation for every day') and spiritual changes ('better understanding of spiritual issues, increase in religiousness'). In the PTGI, participants were asked to rate 21 positive statements that describe the various changes resulting from traumatic or highly challenging events which were provided at the beginning of the inventory. Participants were instructed to focus on their diagnosis of arthritis as an example of a highly stressful event which could be related to positive changes comprising PTG. The statistical analysis is usually performed only for the global PTG score (sum of all items), as the particular subscales in the Polish version of PTGI are highly intercorrelated (Ogińska-Bulik and Juczyński 2010). Unifactorial assessment of PTG is also recommended by some authors (Park and Helgeson 2006). The analysis in this study was conducted according to these recommendations. Cronbach's $\alpha$ in the studied sample for the whole scale was $\alpha=.82$.

Social support was measured by the adapted Polish version (Łuszczyńska et al. 2006) of Schulz and Schwarzer's (2003) Berlin Social Support Scales (BSSS). In this study, two social support scales were used: received support and provided support. In the BSSS, participants refer to a number of statements about social support (e.g., from family, friends, acquaintances, 
children etc.) and specify to what extent the statement reflects their beliefs using a Likert scale ranging from 1 ("Completely not true") to 4 ("Completely true"). The psychometric properties of the Polish version of the BSSS have been assessed on various groups of patients, including those having undergone bypass operations or having experienced heart attacks as well as patients with chronic degenerative spinal diseases (Łuszczyńska et al. 2006). Cronbach's $\alpha$ reliability coefficients for received support and provided support in the studied sample were .81 and .83 , respectively.

To evaluate the level of subjectively possessed resources among participants, we used the COR-E (Hobfoll 1998) in a Polish adaptation by Dudek et al. (2006). In this study, we used the shorter version, which consists of 40 items describing resources related to the following categories: hedonic and vital resources, spiritual resources, family resources, economic and political resources and power and prestige resources. The questionnaire consists of two parts. In Part A, participants rate the importance of the aforementioned categories of resources on a Likert scale ranging from 1 ("Not important") to 5 ("Very important"). In Part B, participants answer the same questions and rate to what extent each of the resource categories characterize them at a given moment from 0 ("I do not possess this particular resource at all") to 5 ("I possess this particular resource to a great extent"). The level of particular subgroups of resources, as well as the global resource indicator, was obtained by multiplying the value of importance of the resources by the current state of possession of those resources. Cronbach's $\alpha$ in the studied sample for the global scale was $\alpha=.78$, and for the four subscales, it varied between .76 and 81 .

\section{Data Analysis}

Data analysis was conducted with the use of the IBM SPSS 24 statistical package (IBM Corp. Released 2016). The introductory part of the statistical analysis consisted of descriptive statistics and Pearson's correlation coefficients between the analysed variables. The main part of the analysis was performed with PROCESS macro based on model No. 4, a model that allows for testing of multiple mediators, one explaining variable and one explained variable. There were two explaining variables received and provided support which were tested in two distinct models of mediation. Each model was concerned with four parallel mediators: hedonic and vital resources, spiritual resources, family resources and economical and political resources. The explained variable in each of the two models was the level of PTG. The mediation effects were verified with the use of a test based on bootstrap sampling with the number of bootstrap samples equal to 5000 .

\section{Results}

Table 2 presents descriptive statistics for all analysed interval variables.

Power and prestige resources were not included in the analysis because of lack of statistically significant relationship with the explained variable. The values of skewness and kurtosis fell in the range between -1 and 1 , and therefore the use of parametric statistical methods was appropriate. Pearson's correlation coefficients revealed positive relationships between provided support and the levels of spiritual, family and economic and political resources, between provided support and received support, between post-traumatic growth and all of the COR resources and between PTG and provided support.

In order to verify the first hypothesis, regression coefficients computed with the use of PROCESS macro in the models of mediation were used. In the total-effect model, the relationship between received support and PTG was statistically insignificant $(B=.03, t=.18, p>.05)$. The model performed statistical control over level of education $(B=-2.75, t=-1.99, p<.05)$ and living in the city $(B=-3.49, t=-2.59, p<.05)$. Both a higher level of education and living in the city were negatively related to the level of PTG.

Likewise, in the total-effect model, the relationship between provided support and PTG was statistically insignificant $(B=.30, t=1.38, p>.05)$. The model also performed

Table 2 Descriptive statistics and pearson correlation coefficients between analysed variables

\begin{tabular}{|c|c|c|c|c|c|c|c|c|c|c|c|}
\hline Variables & $M$ & $S D$ & $S$ & $K$ & 1. & 2. & 3. & 4. & 5. & 6. & 7. \\
\hline 1. Hedonistic and vital resources & 143.94 & 49.55 & .13 & .01 & - & & & & & & \\
\hline 2. Spiritual resources & 108.23 & 30.50 & .07 & -.06 & $.403 * *$ & - & & & & & \\
\hline 3. Family resources & 172.43 & 44.48 & -.97 & .58 & $.290 * *$ & $.413 * *$ & - & & & & \\
\hline 4. Economic and political resources & 118.11 & 39.82 & .02 & -.51 & $.599 * *$ & $.513 * *$ & $.568 * *$ & - & & & \\
\hline 5. Received support & 38.86 & 7.60 & -.06 & .36 & .041 & .072 & .088 & .071 & - & & \\
\hline 6. Provided support & 36.60 & 6.02 & -.44 & .37 & .107 & $.181 * *$ & $.270 * *$ & $.167^{*}$ & $.593 * *$ & - & \\
\hline 7. Post-traumatic growth & 66.13 & 19.00 & -0.92 & .82 & $.206^{* *}$ & $.407 * *$ & $.262 * *$ & $.237 * *$ & .040 & $.139 *$ & - \\
\hline
\end{tabular}

$M$, mean value; $S D$, standard deviation; $S$, skewness; $K$, kurtosis

$* p<.05 ; * * p<.01$ 
statistical control over level of education $(B=-2.37, t=$ $-1.79, p<.05)$ and living in the city $(B=-3.45, t=-2.57$, $p<.05)$. There was a positive correlation between provided support and PTG (see Table 2), which was consistent with the first hypothesis.

In order to verify the second hypothesis, mediation analysis was performed. Received and provided support were analysed as explaining variables, the levels of resources as mediators and PTG as an explained variable. Figure 1 presents the assumed relationships between the analysed variables.

There were three analysed types of paths. There was path a between explaining variable and mediators, path $b$ between mediators and explained variable and path $\mathrm{c}$ between explaining variable and explained variable, total (c) and direct (c') with statistical controls over the mediators.

Table 3 presents the acquired regression coefficients of the mediation analysis along with the values of the statistical test for mediation effects based on bootstrap sampling. In the model concerned with received support there were no relationships between the explaining variable and the assumed mediators, i.e. COR resources. As a consequence, the indirect-effects test was also statistically insignificant. There was only statistically significant positive relationship between spiritual resources and PTG, but spiritual resources were not related to received support which indicates that spiritual resources cannot function as a mediator of the relationship between received support and PTG, as it would require at least both, path $\mathrm{a}$ and $\mathrm{b}$ to be statistically significant.

In the model concerned with provided support, the explaining variable was positively related to the level of spiritual, family and economical and political resources. The level of spiritual resources was then positively related to PTG, while the level of family resources and economical and political resources were not. The indirect-effects test was statistically significant for the level of spiritual resources, which means that the level of spiritual resources is a mediator of the relationship between provided support and PTG.

Besides the statistical controls of living in the city and level of education, there were also statistically significant relationships

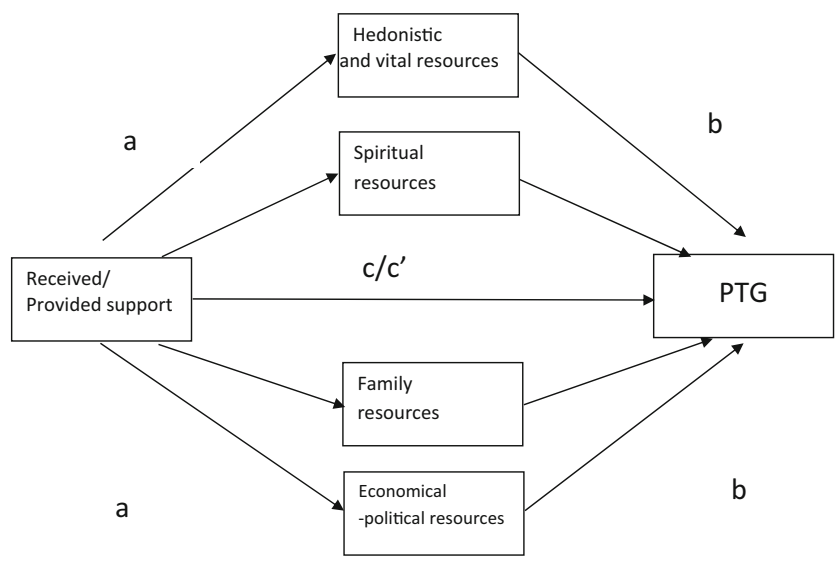

Fig. 1 Hypothesised relationships between analysed variables between participants' age and level of resources, which were controlled for in the analysed models. Participants' age was positively related to the level of spiritual resources $(B=.29, t=1.96$, $p<.05)$ and the level of family resources $(B=.69, t=3.34$, $p<.01)$ and negatively related to the level of hedonic and vital resources $(B=-.85, t=-3.46, p<.01)$.

\section{Discussion}

The results of this study were partly in accordance with the first hypothesis, as social support was positively related to the level of PTG in arthritis patients. Specifically, the results indicated that the relationship between social support and PTG was related to the much understudied provided support only, yet not to received support. According to Tedeschi and Calhoun (1996, 2004) social support plays an important role in the transition from trauma to growth, as it activates cognitive processes promoting PTG, which has also been empirically demonstrated by several authors (e.g., Brand et al. 2014; Nenova et al. 2011). In the case of arthritis patients, possessing a supportive environment, having the opportunity to self-disclose and receiving help due to experienced disability may be especially valuable. In fact, several authors have shown that social support in arthritis patients is related to quality of life, functional disability and pain while also having long-term effects (Evers et al. 2003; Fyrand et al. 2002; Holtzman et al. 2004; Krol et al. 1993). Consequently, social support is associated with better physical and psychological health and the lack of it may result in worse health outcomes, such as poorer pain adjustment (Evers et al. 2003; López-Martínez et al. 2008). On the other hand, pain may also have an opposite effect by encouraging pain behaviour that contributes to higher levels of pain. This may occur because of significant others showing concern or punishment for expressed pain, leading to less acceptance, avoidance of pain and higher levels of pain due to social support (McClelland and McCubbin 2008; McCracken 2005).

The second hypothesis was also confirmed up to a point, as the relationship between social support (provided) and PTG was mediated solely by the level of spiritual resources. In the past several years, spirituality has become an object of interest to health psychologists who have claimed to broaden the traditional biopsychosocial model with spiritual factors (Pargament et al. 2013). Spirituality may also be relevant for individuals struggling with chronic diseases by helping them to accept their condition, find meaning and seek support in a higher power, which has been observed especially among arthritis patients (Abraido-Lanza et al. 2004). Furthermore, engagement in spiritual issues is beneficial when confronting pain and appears to be the most commonly used method of coping in this patient group (Matthews et al. 2001). It might also be relevant to differentiate between religiousness and spirituality. Religion could be defined as a system of faith 
Table 3 The results of regression analysis of relationships between received and provided support and PTG mediated by the levels of resources

\begin{tabular}{|c|c|c|c|c|c|c|c|c|c|c|c|c|}
\hline \multirow[t]{2}{*}{ Support } & \multirow[t]{2}{*}{ Resources } & \multicolumn{3}{|c|}{ Path a } & \multicolumn{3}{|c|}{ Path b } & \multicolumn{4}{|l|}{ Path c } & \multirow[b]{2}{*}{ Indirect effec } \\
\hline & & $\mathrm{B}$ & $\mathrm{t}$ & $\mathrm{p}$ & $\mathrm{B}$ & $\mathrm{t}$ & $\mathrm{p}$ & & B & $\mathrm{t}$ & $\mathrm{p}$ & \\
\hline \multirow[t]{4}{*}{ Received } & Hedonistic and vital & .23 & .51 & .608 & .05 & 1.52 & .131 & total & .03 & .18 & .855 & $-.06 \div .09$ \\
\hline & Spiritual & .26 & .92 & .359 & .21 & 4.44 & .001 & direct & -.03 & -.19 & .848 & $-.08 \div .23$ \\
\hline & Family & .36 & .92 & .359 & .02 & .43 & .667 & & & & & $-.04 \div .07$ \\
\hline & Economical and political & .30 & .82 & .414 & -.03 & -.68 & .499 & & & & & $-.09 \div .04$ \\
\hline \multirow[t]{4}{*}{ Provided } & Hedonistic and vital & .90 & 1.57 & .118 & .05 & 1.52 & .130 & total & .30 & 1.38 & .170 & $-.05 \div .19$ \\
\hline & Spiritual & .88 & 2.48 & .014 & .21 & 4.39 & .001 & direct & .08 & .40 & .692 & $.02 \div .40$ \\
\hline & Family & 1.75 & 3.63 & .001 & .01 & .35 & .730 & & & & & $-.13 \div .19$ \\
\hline & Economical and political & 1.07 & 2.29 & .023 & -.31 & -.68 & .497 & & & & & $-.19 \div .08$ \\
\hline
\end{tabular}

$B$, unstandardized regression coefficients; $t$, test of predictor's significance; $p$ - statistical significance

recognizing a higher power where performance of faith-related activities and social practices often take place (Pargament et al. 2013). On the other hand, spirituality is seen as search and expression of meaning, connectedness to self, others, and nature and search for the divine. Religion is not necessarily part of spirituality, while a form of spirituality is generally incorporated in religion. The sample in this study consisted of Polish patients and it might be worth mentioning that over $90 \%$ of the population in Poland is religious (Central Statistical Office of Poland 2015). Thus, the measured spirituality and its relation to social support and PTG could be influenced by the possibility that many participants might be religious. Regarding PTG, several authors have found a positive association between spirituality and this positive phenomenon (e.g., Currier et al. 2012; Garland et al. 2007; Gerber et al. 2011; Taku and Cann 2014). When it comes to arthritis patients, one study showed that spirituality was positively related to PTG and that it also mediated the relationship between a return to religion (as stress-coping strategy) and PTG among arthritis patients (Rzeszutek et al. 2017b). In our study, a link was observed between PTG and the spiritual resources (defined by the COR theory as some intrapsychic properties) of an individual, which indicates further direction for research in this area.

Finally, we did not observe statistically significant relationship between sociodemographic and clinical variables with PTG among our participants. It is especially interesting that illness duration was not associated with PTG in our sample, which has also been observed in other studies on PTG in this patient group (Rzeszutek et al. 2017b). There is no agreement on the time elapsed after trauma for growth to occur (Linley and Joseph 2004), which is particularly discussed in the case of illnessrelated trauma: authors observed positive (Sears et al. 2003), negative (Gunst et al. 2016) or lack of relationship (Bellizzi and Blank 2006) between time since disease diagnosis and PTG. Tedeschi and Calhoun (1996, 2004) mentioned that PTG is not a static outcome but a complex process, rather unlikely to occur shortly after trauma, which may explain the aforementioned inconclusive findings. Łuszczyńska et al. (2012) specified that PTG shortly after a chronic or terminal illness diagnosis may act as a palliative response to a life threat, but in the long perspective may be linked to more profound positive life changes. However, this latter hypothesis can be verified only in longitudinal studies, which are still scarce in PTG research, including studies on PTG among arthritis patients.

\section{Strengths and Limitations}

This theory-driven study is the first to explore the link between social support and PTG among arthritis patients from the perspective of the COR theory, which is its strength. However, a few limitations should be mentioned. First, relatively few medical variables were controlled among the participants. Additionally, the cross-sectional design of the study precludes causal interpretation of the obtained results. In particular, taking the aforementioned shortcomings into account, we were not able to assess the resource loss or resource gain over time among the participants, only the level of subjectively evaluated resources. Finally, the study sample was heterogeneous in terms of arthritis diagnosis and duration of the disease. Future studies should be based on a more homogenous study sample in this regard.

\section{Conclusion}

Despite its limitations, the results of this study increase the understanding and knowledge of the psychological aspects of arthritis and contribute to the literature by exploring the link between social support and PTG in a COR framework. It seems that providing support may be related to positive 
consequences in the form of PTG among arthritis patients and that spiritual resources are of significant value in this process.

Compliance with Ethical StandardsAll procedures performed in studies involving human participants were in accordance with the ethical standards of the institutional and/or national research committee and with the 1964 Helsinki declaration and its later amendments or comparable ethical standards.

Informed Consent Informed consent was obtained from all individual participants included in the study.

Conflict of Interest Author A declares that she has no conflict of interest. Author B declares that he has no conflict of interest. Author C declares that he has no conflict of interest.

Open Access This article is distributed under the terms of the Creative Commons Attribution 4.0 International License (http:// creativecommons.org/licenses/by/4.0/), which permits unrestricted use, distribution, and reproduction in any medium, provided you give appropriate credit to the original author(s) and the source, provide a link to the Creative Commons license, and indicate if changes were made.

Publisher's Note Springer Nature remains neutral with regard to jurisdictional claims in published maps and institutional affiliations.

\section{References}

Abraido-Lanza, A. F., Guier, C., \& Colón, R. M. (1998). Psychological thriving among Latinas with chronic illness. Journal of Social Issues, 54(2), 405-424. https://doi.org/10.1111/j.1540-4560.1998.tb01227.x.

Abraido-Lanza, A. F., Vásquez, E., \& Echeverría, S. E. (2004). Religious and other forms of coping among Latinos with arthritis. Journal of Consulting and Clinical Psychology, 72(1), 91-102. https://doi.org/ 10.1037/0022-006X.72.1.91.

Banou, E., Hobfoll, S. E., \& Trochelman, R. D. (2009). Loss of resources as mediators between interpersonal trauma and traumatic and depressive symptoms among women with cancer. Journal of Health Psychology, 14(2), 200-214. https://doi.org/10.1177/ 1359105308100204

Batson, C. D., \& Powell, A. A. (2003). Altruism and prosocial behavior. In T. Millon \& M. J. Lerner (Eds.), Handbook of psychology: Personality and social psychology (Vol. 5, pp. 463-484). Hoboken, NJ, US: John Wiley \& Sons Inc.. https://doi.org/10. 1002/0471264385.wei0519.

Bellizzi, K. M., \& Blank, T. (2006). Predicting posttraumatic growth in breast cancer survivors. Health Psychology, 25(1), 47-56. https:// doi.org/10.1037/0278-6133.25.1.47.

Benka, J., Nagyova, I., Rosenberger, J., Macejova, Z., Lazurova, I., Van der Klink, J. J. L., et al. (2014). Is coping self-efficacy related to psychological distress in early and established rheumatoid arthritis patients. Journal of Developmental and Physical Disabilities, 26(3), 285-297. https://doi.org/10.1007/s10882-013-9364-y.

Bolger, N., Foster, M., Vinokur, A. D., \& Ng, R. (1996). Close relationships and adjustment to a life crisis: The case of breast cancer. Journal of Personality and Social Psychology, 70(2), 283-294. https://doi.org/10.1037/0022-3514.70.2.283.

Brand, C., Barry, L., \& Gallagher, S. (2014). Social support mediates the association between benefit finding and quality of life in caregivers. Journal of Health Psychology, 21(6), 1126-1136. https://doi.org/10. 1177/1359105314547244.
Calhoun, L. G., Tedeschi, R. G., Cann, A., \& Hanks, E. A. (2010). Positive outcomes following bereavement: Paths to posttraumatic growth. Psychologica Belgica, 50(1-2), 125-143. https://doi.org/ 10.5334/pb-50-1-2-125.

Central Statistical Office of Poland. (2015). Uczestnictwo w mszach i poczucie związku z parafia [holy mass participation and feeling of attachment with the parish church in Poland]. Retrieved November 08, 2018 from https://stat.gov.pl/files/gfx/portalinformacyjny/pl/ defaultaktualnosci/5500/3/1/1/bss_folder_zycie_religijne.pdf.

Currier, J., Malott, J. D., Martinez, T., Sandy, C., \& Neimeyer, R. A. (2012). Bereavement, religion, and posttraumatic growth: A matched control group investigation. Psychology of Religion and Spirituality, 5(2), 69-77. https://doi.org/10.1037/a0027708.

Dager, T. N., Kjeken, I., Fjerstad, E., \& Hauge, M. (2011). "It is about taking grips and not let myself be ravaged by my body": A qualitative study of outcomes from in-patient multidisciplinary rehabilitation for patients with chronic rheumatic diseases. Disability \& Rehabilitation, 34(11), 910-916. https://doi.org/10.3109/ 09638288.2011 .626485 .

Danoff-Burg, S., \& Revenson, T. (2005). Benefit-finding among patients with rheumatoid arthritis: Positive effects on interpersonal relationships. Journal of Behavioral Medicine, 28(1), 91-103. https://doi. org/10.1007/s10865-005-2720-3.

Dirik, G., \& Karanci, A. N. (2008). Variables related to posttraumatic growth in Turkish rheumatoid arthritis patients. Journal of Clinical Psychology in Medical Settings, 15(3), 193-203. https://doi.org/10. 1007/s10880-008-9115-x.

Dirik, G., \& Karanci, A. N. (2009). Psychological distress in rheumatoid arthritis patients: An evaluation within the conservation of resource theory. Psychology and Health, 25(5), 617-632. https://doi.org/10. 1080/08870440902721818.

Dudek, B., Gruszczyńska, E., \& Koniarek, J. (2006). Teoria zachowania zasobów S. Hobfolla — zagadnienia teoretyczne i metodologiczne oraz adaptacja kwestionariusza COR-Evaluation. In T. Pasikowski \& H. Sęk (Eds.), Psychologia zdrowia: teoria, metodologia $i$ empiria (pp. 51-60). Poznań: Bogucki Wydawnictwo Naukowe.

Edlund, M. J., Sullivan, M. D., Han, X., \& Booth, B. M. (2013). Days with pain and substance use disorders: Is there an association? The Clinical Journal of Pain, 29(8), 689-695. https://doi.org/10.1097/ AJP.0b013e318270fa77.

Evers, A. W. M., Kraaimaat, F. W., Geenen, R., Jacobs, J. W. G., \& Bijlsma, J. W. J. (2003). Pain coping and social support as predictors of long-term functional disability and pain in early rheumatoid arthritis. Behaviour Research and Therapy, 41(11), 1295-1310. https://doi.org/10.1016/S0005-7967(03)00036-6.

Frankl, V. E. (1992). Man's search for meaning: An introduction to logotherapy (4th ed.) (I. Lasch, Trans.). Boston: Beacon Press.

Fyrand, L., Moum, T., Finset, A., \& Glennås, A. (2002). The impact of disability and disease duration on social support of women with rheumatoid arthritis. Journal of Behavioral Medicine, 25(3), 251268. https://doi.org/10.1023/A:1015380711375.

Garland, S. N., Carlson, L., Cook, S., Lansdell, L., \& Speca, M. (2007). A non-randomized comparison of mindfulness-based stress reduction and healing arts programs for facilitating post-traumatic growth and spirituality in cancer outpatients. Support Care Cancer, 15(8), 949961. https://doi.org/10.1007/s00520-007-0280-5.

Gerber, M. M., Boals, A., \& Schuettler, D. (2011). The unique contributions of positive and negative religious coping to posttraumatic growth and PTSD. Psychology of Religion and Spirituality, 3(4), 298-307. https://doi.org/10.1037/a0023016.

Gleason, M. E. J., Iida, M., Shrout, P. E., \& Bolger, N. (2008). Receiving support as a mixed blessing: Evidence for dual effects of support on psychological outcomes. Journal of Personality and Social Psychology, 94(5), 824-838. https://doi.org/10.1037/0022-3514.94.5.824.

Goeppinger, J., Armstrong, B., Schwartz, T., Ensley, D., \& Brady, T. (2007). Self-management education for persons with arthritis: Managing 
comorbidity and eliminating health disparities. Arthritis and Rheumatism, 57(6), 1081-1088. https://doi.org/10.1002/art.22896.

Gunst, D. C. M., Kaatsch, P., \& Goldbeck, L. (2016). Seeing the good in the bad: Which factors are associated with posttraumatic growth in long-term survivors of adolescent cancer? Support Care Cancer, 24(11), 4607-4615. https://doi.org/10.1007/s00520-016-3303-2.

Hansen, S. M., Hetland, M. L., Pedersen, J., Østergaard, M., Erichsen, T. S. R., \& Bjorner, J. B. (2017). Work ability in rheumatoid arthritis patients: A register study on the prospective risk of exclusion and probability of returning to work. Rheumatology (Oxford, England), 56(7), 1135-1143. https://doi.org/10.1093/rheumatology/kex064.

Hefferon, K., Grealy, M., \& Mutrie, N. (2008). Post-traumatic growth and life threatening physical illness: A systematic review of the qualitative literature. British Journal of Health Psychology, 14(2), 343378. https://doi.org/10.1348/135910708X332936.

Hobfoll, S. E. (1989). Conservation of resources: A new attempt at conceptualizing stress. American Psychologist, 44(3), 513-524. https:// doi.org/10.1037/0003-066X.44.3.513.

Hobfoll, S. E. (1998). The plenum series on stress and coping. Stress, culture, and community: The psychology and philosophy of stress. New York: Plenum Press.

Hobfoll, S. E., Tracy, M., \& Galea, S. (2006). The impact of resource loss and traumatic growth on probable PTSD and depression following terrorist attacks. Journal of Traumatic Stress, 19(6), 867-878. https://doi.org/10.1002/jts.20166.

Hollifield, M., Gory, A., Siedjak, J., Nguyen, L., Holmgreen, L., \& Hobfoll, S. (2016). The benefit of conserving and gaining resources after trauma: A systemic review. Journal of Clinical Medicine, 5(11), 104. https://doi.org/10.3390/jcm5110104.

Holtzman, S., Newth, S., \& DeLongis, A. (2004). The role of social support in coping with daily pain among patients with rheumatoid arthritis. Journal of Health Psychology, 9(5), 677-695. https://doi. org/10.1177/1359105304045381.

Hou, W. K., Law, C. C., \& Fu, Y. (2010). Does change in positive affect mediate and/or moderate the impact of symptom distress on psychological adjustment after cancer diagnosis? A prospective analysis. Psychology \& Health, 25(4), 417-431. https://doi.org/10.1080/ 08870440802559375.

IBM Corp. Released. (2016). IBM SPSS Statistics for Windows. Version 24. Armonk: IBM Corp.

Jafarzadeh, S. R., \& Felson, D. T. (2017). Updated estimates suggest a much higher prevalence of arthritis in United States adults than previous ones. Arthritis \& Rheumatology, 70(2), 185-192. https:// doi.org/10.1002/art.40355.

Klauer, T., Ferring, D., \& Filipp, S. H. (1998). "Still stable after all this...?": Temporal comparisons in coping with severe and chronic disease. International Journal of Behavioral Development, 22(2), 339-355. https://doi.org/10.1080/016502598384405.

Kleiboer, A., Kuijer, R., Hox, J., Schreurs, K. M. G., \& Bensing, J. M. (2006). Receiving and providing support in couples dealing with multiple sclerosis: A diary study using an equity perspective. Personal Relationships, 13(4), 485-501. https://doi.org/10.1111/j. 1475-6811.2006.00131.x.

Kotsis, K., Voulgari, P. V., Tsifetaki, N., Machado, M. O., Carvalho, A. F., Creed, F., et al. (2012). Anxiety and depressive symptoms and illness perceptions in psoriatic arthritis and associations with physical health-related quality of life. Arthritis Care \& Research, 64(10), 1593-1601. https://doi.org/10.1002/acr.21725.

Krol, B., Sanderman, R., \& Suurmeijer, T. P. B. M. (1993). Social support, rheumatoid arthritis and quality of life: Concepts, measurement and research. Patient Education and Counseling, 20(2-3), 101-120. https://doi.org/10.1016/0738-3991(93)90125-G.

Lazarus, R. S., \& Folkman, S. (1984). Stress, appraisal, and coping. New York: Springer
Linley, P. A., \& Joseph, S. (2004). Positive change following trauma and adversity: A review. Journal of Traumatic Stress, 17(1), 11-21. https://doi.org/10.1023/B:JOTS.0000014671.27856.7e.

López-Martínez, A. E., Esteve, R., \& Ramírez-Maestre, C. (2008). Perceived social support and coping responses are independent variables explaining pain adjustment among chronic pain patients. Journal of Pain, 9(4), 373-379. https://doi.org/10.1016/j.jpain. 2007.12.002.

Łuszczyńska, A., Kowalska, M., Mazurkiewicz, M., \& Schwarzer, R. (2006). Berlińskie skale wsparcia społecznego (BSSS): Wyniki wstępnych badań nad adaptacją skal i ich własnośnciami psychometrycznymi [Berlin social support scales (BSSS): Polish version of BSSS and preliminary results on its psychometric properties]. Studia Psychologiczne, 44(3), 17-27. Retrieved July 18, 2018.

Łuszczyńska, A., Durawa, A. B., Dudzińska, M., Kwiatkowska, M., Knysz, B., \& Knol, N. (2012). The effects of mortality reminders on posttraumatic growth and finding benefits among patients with life-threatening illness and their caregivers. Psychology \& Health 27(10), 1227-1243. https://doi.org/10.1080/08870446.2012. 665055.

Matcham, F., Rayner, L., Steer, S., \& Hotopf, M. (2013). The prevalence of depression in rheumatoid arthritis: A systematic review and metaanalysis. Rheumatology, 52(12), 2136-2148. https://doi.org/10. 1093/rheumatology/ket169.

Matthews, D. A., Marlowe, S. M., \& MacNutt, F. S. (2001). Effects of intercessory prayer on patients with rheumatoid arthritis. Southern Medical Journal, 93(12), 1177-1186. https://doi.org/10.1097/ 00007611-200012000-00008.

McClelland, L. E., \& McCubbin, J. A. (2008). Social influence and pain response in women and men. Journal of Behavioral Medicine, 31(5), 413-420. https://doi.org/10.1007/s10865-008-9163-6.

McCracken, L. (2005). Social context and acceptance of chronic pain: The role of solicitous and punishing responses. Pain, 113(1-2), 155-159. https://doi.org/10.1016/j.pain.2004.10.004.

Morelli, S. A., Lee, I. A., Arnn, M. E., \& Zaki, J. (2015). Emotional and instrumental support provision interact to predict well-being. Emotion, 15(4), 484-493. https://doi.org/10.1037/emo0000084.

Nenova, M., DuHamel, K., Zemon, V., Rini, C. M., \& Redd, W. H. (2011). Posttraumatic growth, social support, and social constraint in hematopoietic stem cell transplant survivors. Psychooncology, 22(1), 195-202. https://doi.org/10.1002/pon.2073.

Ogińska-Bulik, N., \& Juczyński, Z. (2010). Posttraumatic growth Characteristic and measurement. Psychiatria, 7(4), 129-142 ISSN 1732-9841.

O'Leary, V. E., \& Ickovics, J. R. (1995). Resilience and thriving in response to challenge: An opportunity for a paradigm shift in women's health. Women's Health: Research on Gender: Behavior and Policy, 1(2), 121-142.

Pargament, K., Mahoney, A., Shafranske, E., Exline, J., \& Jones, J. (2013). From research to practice: Towards an applied psychology of religion and spirituality. In K. Pargament, A. Mahoney, \& P. Shafranske (Eds.), APA handbook of psychology, religion, and spirituality: An applied psychology of religion and spirituality (Vol. 2, pp. 3-22). Washington: American Psychological Association.

Park, C. L., \& Helgeson, V. S. (2006). Introduction to the special section: Growth following highly stressful life events - current status and future directions. Journal of Consulting and Clinical Psychology, 74(5), 791-796. https://doi.org/10.1037/0022-006X.74.5.791.

Purc-Stephenson, R. (2014). The posttraumatic growth inventory: Factor structure and invariance among persons with chronic diseases. Rehabilitation Psychology, 59(1), 10-18. https://doi.org/10.1037/ a0035353.

Roddy, E., Muller, S., Hayward, R. A., \& Mallen, C. (2013). The association of gout with sleep disorders: A cross-sectional study in 
primary care. BMC Musculoskeletal Disorders, 14, 119. https://doi. org/10.1186/1471-2474-14-119.

Rzeszutek, M., Oniszczenko, W., \& Firlag-Burkacka, E. (2017a). Social support, stress coping strategies, resilience and posttraumatic growth in a polish sample of HIV-infected individuals: Results of a 1 year longitudinal study. Journal of Behavioral Medicine, 40(6), 942954. https://doi.org/10.1007/s10865-017-9861-z.

Rzeszutek, M., Oniszczenko, W., \& Kwiatkowska, B. (2017b). Stress coping strategies, spirituality, social support and posttraumatic growth in a polish sample of rheumatoid arthritis patients. Psychology, Health \& Medicine, 22(9), 1082-1088. https://doi.org/ 10.1080/13548506.2017.1280174.

Sato, M., Yamazaki, Y., Sakita, M., \& Bryce, T. J. (2008). Benefit-finding among people with rheumatoid arthritis in Japan. Nursing and Health Sciences, 10(1), 51-58. https://doi.org/10.1111/j.14422018.2007.00372.x.

Scholz, U., Kliegel, M., Łuszczyńska, A., \& Knoll, N. (2012). Associations between received social support and positive and negative affect: Evidence for age differences from a daily-diary study. European Journal of Ageing, 9(4), 361-371. https://doi.org/10. 1007/s10433-012-0236-6.

Schulz, U., \& Schwarzer, R. (2003). Soziale Unterstützung bei der Krankheitsbewältigung. Die Berliner Social Support Skalen (BSSS) [Social support in coping with illness: The Berlin Social Support Scales (BSSS)]. Diagnostica, 49(2), 73-82. https://doi. org/10.1026//0012-1924.49.2.73.

Sears, S. R., Stanton, A. L., \& Danoff-Burg, S. (2003). The yellow brick road and the emerald city: Benefit-finding, positive reappraisal coping, and posttraumatic growth in women with early stage breast cancer. Health Psychology, 22(5), 487-497. https://doi.org/10. 1037/0278-6133.22.5.487.

Seligman, M. E., \& Csikszentmihalyi, M. (2000). Positive psychology: An introduction. American Psychologist, 55(1), 5-14. https://doi. org/10.1037/0003-066X.55.1.5.

Shen, C. C., Hu, L. Y., Yang, A. C., Kuo, B. I. T., Chiang, Y. Y., \& Tsai, S. J. (2016). Risk of psychiatric disorders following ankylosing spondylitis: A nationwide population-based retrospective cohort study. The Journal of Rheumatology, 43(3), 625-631. https://doi.org/10. 3899/jrheum. 150388 .
Shih, M., Hootman, J. M., Strine, T., Chapman, D. P., \& Brady, T. J. (2006). Serious psychological distress in U.S. adults with arthritis. Journal of General Internal Medicine, 21(11), 1160-1166. https:// doi.org/10.1111/j.1525-1497.2006.00573.x.

Sirois, F. M., \& Hirsch, J. K. (2013). Associations of psychological thriving with coping efficacy, expectations for future growth, and depressive symptoms over time in people with arthritis. Journal of Psychosomatic Research, 75(3), 279-286. https://doi.org/10.1016/ j.jpsychores.2013.06.004.

Smolen, J. S., Aletaha, D., \& Mcinnes, I. B. (2016). Rheumatoid arthritis. The Lancet, 388(10055), 2023-2038. https://doi.org/10.1016/ S0140-6736(16)30173-8.

Taku, K., \& Cann, A. (2014). Cross-national and religious relationships with posttraumatic growth: The role of individual differences and perceptions of the triggering event. Journal of Cross-Cultural Psychology, 45(4), 601-617. https://doi.org/10.1177/ 0022022113520074.

Tang, N. K. Y., \& Crane, C. (2006). Suicidality in chronic pain: A review of the prevalence, risk factors and psychological links. Psychological Medicine, 36(5), 575-586. https://doi.org/10.1017/ S0033291705006859.

Taylor-Gjevre, R., Gjevre, J. A., Skomro, R., \& Nair, B. V. (2011). Assessment of sleep health in patients with rheumatic disease. International Journal of Clinical Rheumatology, 6(2), 207-218. https://doi.org/10.2217/ijr.11.6.

Tedeschi, R. G., \& Calhoun, L. G. (1996). The posttraumatic growth inventory: Measuring the positive legacy of trauma. Journal of Traumatic Stress, 9(3), 455-471. https://doi.org/10.1007/ BF02103658.

Tedeschi, R. G., \& Calhoun, L. G. (2004). Posttraumatic growth: Conceptual foundations and empirical evidence. Psychological Inquiry, 15(1), 1-18. https://doi.org/10.1207/s15327965pli1501_ 01.

Wikström, I., Book, C., \& Jacobsson, L. T. H. (2006). Difficulties in performing leisure activities among persons with newly diagnosed rheumatoid arthritis: A prospective, controlled study. Rheumatology, 45(9), 1162-1166. https://doi.org/10.1093/rheumatology/kel080. 